\title{
R On T Phenomenon by ECG Finding
}

National Cancer Institute

\section{Source}

National Cancer Institute. R On T Phenomenon by ECG Finding. NCI Thesaurus. Code C61395.

An electrocardiographic finding in which the $\mathrm{R}$ wave of a premature ventricular complex occurs on top of the T wave of the preceding beat. (CDISC) 